\title{
Distribution of Calpains I and II in Rat Brain
}

\author{
Takao Hamakubo, ${ }^{*, 1}$ Reiji Kannagi, $†$ Takashi Murachi, $\dagger$ and Andrew Matus* \\ ${ }^{*}$ Friedrich Miescher-Instilut, CH-4002 Basel, Switzerland, and †Department of Clinical Science and Laboratory \\ Medicine, Kyoto University Faculty of Medicine, Kyoto 606, Japan
}

\begin{abstract}
Calpains I and II are calcium-dependent proteases that have been implicated in several aspects of brain function, including neurofilament turnover, Wallerian degeneration, and excitatory synaptic transmission. In this study, specific affinity-purified antibodies against each of the enzymes were used to determine their cellular distribution in rat brain. Differences between the two were found throughout the brain, with calpain I being located primarily in neurons, whereas calpain II was more prominent in glial cells. In myelinated axons, calpain II was present at low levels but calpain I was not detectable. In all brain areas, both enzymes were concentrated in cell bodies, with lesser amounts in neuronal and glial processes. Calpain I was only detectable proximally in dendrites and was not found in spiny branchlets of either pyramidal or Purkinje cells. These results suggest that calpain II is the likely form of the enzyme involved in calcium-activated proteolytic phenomena in axons. They do not support the existence of a role for calpain at excitatory axospinous synapses.
\end{abstract}

Calpain (EC 3.4.22.17; $\mathrm{Ca}^{21}$-dependent cysteine proteinase), first discovered in rat brain (Guroff, 1964), is now known to be widely distributed in various animal species (Murachi et al., 1981a). Two forms of calpain, which differ in their $\mathrm{Ca}^{2+}$ requirement, have been identified: low- (or $\mu \mathrm{M}$ concentration) $\mathrm{Ca}^{2+}$-requiring calpain I and high- (or mM concentration) $\mathrm{Ca}^{2+}$ requiring calpain II (Mellgren, 1980; Murachi et al., 1981b). Both calpains I and II are known to be composed of one heavy (approximately $80 \mathrm{kDa}$ ) and one light (approximately $30 \mathrm{kDa}$ ) subunit. The heavy subunits, each of which contains the active site cysteine residue, differ chemically and immunologically bctween calpains I and II, whereas the light subunits, whose function is not fully understood, are most probably identical (Kitahara et al., 1984; Sasaki et al., 1984; Wheelock, 1982).

While calpains I and II are very widely distributed in various tissues and cells, both the absolute and relative abundance of the two calpains are markedly different from one tissue to another (for a recent review, see Murachi, 1984). In nervous tissue, calpain has been detected in axoplasm from the giant axon of Myxicola (Gilbert and Newby, 1975), in squid (Pant et al., 1979), and in rat peripheral nerve (Kamakura et al., 1983; Schlaepfer and Freeman, 1980). These authors reported selective degradation of axonal neurofilaments and the enzyme's requirement of $\mathrm{Ca}^{2+}$ at the millimolar level for maximal activity, which suggests that the enzyme involved was calpain II. Other investigators reported the existence of a low-Ca ${ }^{2+}$-requiring form, calpain I, in the rat spinal cord (Ishizaki et al., 1983; Tashiro

\footnotetext{
Received Aug. 30, 1985; revised Feb. 10, 1986; accepted Feb. 14, 1986.

Correspondence should be addressed to Dr. Andrew Matus, Friedrich MiescherInstitut, P.O. Box 2543, CH-4002 Basel, Switzerland.

${ }^{1}$ Permanent address: Department of Clinical Science and Laboratory Medicine, Kyoto University Faculty of Medicine, Kyoto 606, Japan.

Copyright (C) 1986 Society for Neuroscience $0270-6474 / 86 / 113103-09 \$ 02.00 / 0$
}

and Ishizaki, 1982). Siman et al. (1983) have reported the recovery of both calpains I and II from synaptosomal plasma membrane, and Lynch and Baudry (1984) have proposed a hypothesis that calpain is involved in the regulation of hippocampal glutamate receptors, which these authors relate to the phenomenon of long-term memory.

A large number of cellular proteins have been reported to be susceptible to calpains (for a review, see Murachi, 1984), but it is still unclear whether all of these proteins are true natural substrates of calpain and, hence, what the true physiological role of calpain inside a cell might be. In view of the wide variety of substrates for calpains in vitro, the localization of the two forms of the enzyme is critical in evaluating their proposed roles in the nervous system. As an approach to this problem, we have studied the distributions of calpains $I$ and II in rat brain using specific antibodies that can discriminate between these 2 enzymes (Yoshimura et al., 1984).

\section{Materials and Methods}

\section{Preparation of antibodies}

Two antibodies directed, respectively, against the calpain I $80 \mathrm{kDa}$ subunit and the calpain II $80 \mathrm{kDa}$ subunit were obtained from rabbits immunized with porcine erythrocyte calpain I $80 \mathrm{kDa}$ subunit and porcine kidney calpain II $80 \mathrm{kDa}$ subunit. Each IgG fraction was further purified by 2 -step affinity chromatography, using the appropriate 80 $\mathrm{kDa}$ subunit protein as the immobilized ligand (Yoshimura et al., 1984). Their mutually discriminative specificity has previously becn established using gel blots of purified calpains and porcine kidney protein (Yoshimura et al., 1984). In all experiments both antibodies were used at $0.05 \mathrm{mg} / \mathrm{ml}$ of protein.

\section{Immunochemical procedures}

Whole brain tissues were homogenized with a Dounce homogenizer in 3 volumes of ice-cold $20 \mathrm{~mm}$ Tris-buffered saline containing $1 \mathrm{~mm}$ EGTA, $5 \mathrm{~mm}$ mercaptoethanol, and $0.25 \mathrm{~m}$ sucrose. After centrifugation at $105,000 \times g$ for $1 \mathrm{hr}$, the supernatant was collected. Proteins of the supernatant were separated by SDS-PAGE according to the method of Laemmli (1970), using gels containing $7.5 \%$ polyacrylamide. Protein blotting onto nitrocellulose membrane (Towbin et al., 1979) and the subsequent immunochemical staining (Matus et al., 1980) were performed as described.

\section{Immunohistochemistry}

Sprague-Dawley rats, aged $0,10,15,20$, and $45 \mathrm{~d}$, and adult animals (older than $70 \mathrm{~d}$ ) were fixed by transcardiac perfusion under Nembutal ancsthcsia, using $4 \%$ paraformaldchyde and $0.75 \%$ glutaraldehyde in $50 \mathrm{~mm}$ PBS. Tissue was sectioned at $40 \mu \mathrm{m}$ using a Vibratome (Oxford). During this procedure, tissues were kept at $4^{\circ} \mathrm{C}$ in Tris-buffered saline. The sections were transferred into 24-well plastic plates, and stained with the antibodies according to the peroxidase-antiperoxidase technique at room temperature, using 4-chloro-1-naphthol as a chromogen (Bernhardt and Matus, 1984). All solutions used were supplemented with $0.05 \%$ Tween-20 to reduce nonspecific staining. The control runs, omitting the first antibody (anti-calpain antibody), gave no positive stainings. 


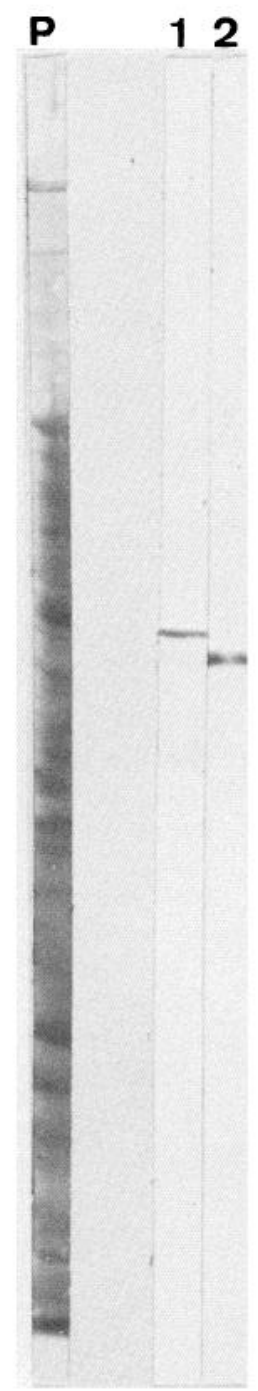

Figure 1. Western blots of the supernatant fraction of total brain homogenate. The proteins were separated by SDS-gel electrophoresis, blotted onto nitrocellulose, and stained for protein $(P)$ or with anti-calpain I (1) or anti-calpain II (2).

\section{Results}

\section{Specificity of the antibodies}

To test whether the antibodies were specific for calpain I and II, respectively, we checked their reactions with the proteins in the supernatant (cytosol) fraction of total rat brain homogenate. As is shown in Figure 1, each antibody reacted with 1 major protein, which was of a molecular size appropriate to each calpain.

The specificity of the 2 antibodies was also indicated by the characteristic staining patterns they gave in brain sections. These were distinct from staining patterns obtained using the same immunoperoxidase technique with rabbit antisera against other brain proteins (e.g., actin: Matus et al., 1982; microtubule-associated protein 2: Bernhardt and Matus, 1984; synaptic membrane proteins: Matus et al., 1984). In addition, characteristic differences were found between the staining patterns with anticalpain I and anti-calapin II. These are described below for 3 major brain regions. For each antibody, the same characteristic pattern was found throughout the brain.
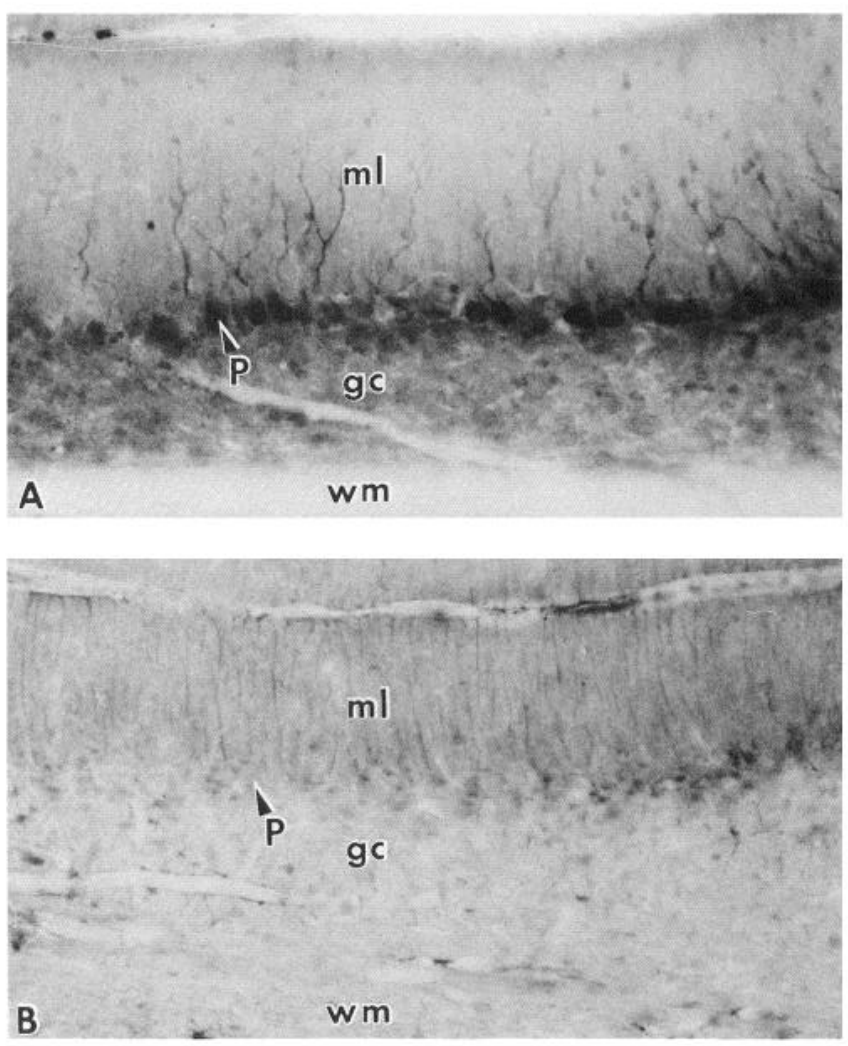

Figure 2. Adult rat cerebellum stained with either anti-calpain I $(A)$ or II $(B) . m l$, Molecular layer; $g c$, granule cell layer; $w m$, white matter; $P$, Purkinje cell layer. Magnification, $\times 100$.

\section{Distribution in cerebellum}

As is shown in Figure 2A, anti-calpain I stained Purkinje cell bodies and their proximal dendrites. Staining intensity was strongest in the Purkinje cell layer, and weaker staining was also observed in the granule cell layer and in interneurons in the molecular layer (ml, Fig. 2A). Anti-calpain II gave a different pattern, in which the radial processes of Bergmann glia were the most prominent feature (Fig. $2 B$ ). At higher magnification, the difference between the staining patterns of anti-calpain I and II was clear (Fig. 3, $A, B$ ). Purkinje cell bodies were intensely stained by anti-calpain I and a weaker reaction was also present in the proximal dendrites (Fig. $3 A$ ). The soma of interneurons were also stained but no staining of processes was detectable. These were the only cellular elements of the cerebellar cortex that showed distinct and reproducible calpain I reactivity. Anticalpain II produced weaker staining of Purkinje cell bodies; in most cells it was extremely faint (for example, the cells labeled $\mathrm{P}_{1}$ and $\mathrm{P}_{3}$ in Fig. $3 B$ ). There were, however, occasional cells that had a stronger reaction (e.g., $\mathrm{P}_{2}$ in Fig. $3 B$ ). Much more consistent was the staining of Bergmann glial cell bodies (" $\mathrm{g}$ " in Fig. $3 B$ ) and their processes. There was no consistent staining of interneurons by anti-calpain II, either in the granule cell or molecular layers.

Both antibodies produced some staining in the proximal dendrites of Purkinje cells, but neither stained the fine branchlets bearing the axospinous synapses of these cells. Another marked difference was seen in the central white matter (Fig. 4). Anticalpain II clearly reacted with myelinated axons, though the staining intensity was weak. By contrast, staining with anticalpain I produced no positive reaction. 

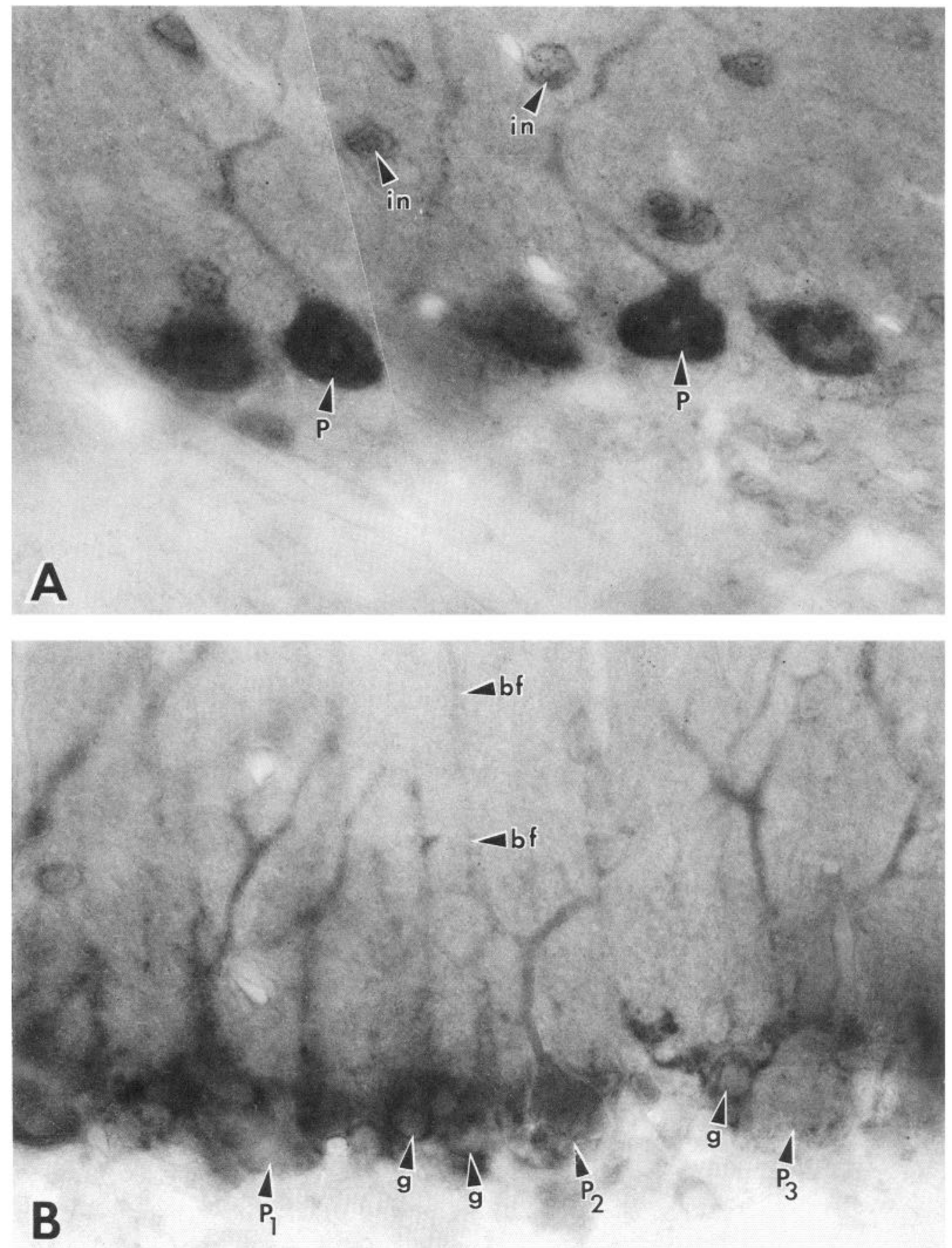

Figure 3. Adult rat cerebellum stained for calpain I $(A)$ or II $(B)$. In $A$, cell bodies of Purkinje cells $(P)$ and interneurons (in) are labeled. In $B$, 3 of the weakly reactive Purkinje cells are indicated $\left(P_{1}\right.$ to $\left.P_{3}\right)$; together with Bergmann glial cell bodies $(g)$ and their processes $(b f)$. Magnification, $\times 500$.

\section{Distribution in cerebral cortex}

The staining pattern in the neocortex was similar to that in the cerebellum. Anti-calpain I mainly stained neuronal cell bodies and the proximal part of their processes (Fig. $5, A, C$ ). On the other hand, anti-calpain II reacted rather strongly with glial cells (Fig. 5, $B, D$ ). Endothelial cells of blood vessels and the glial cells that had contact with blood vessels were stained with anticalpain II. Glial cells stained with anti-calpain II were conspicuous in the area near the pial surface.

\section{Distribution in hippocampus}

A striking difference between the anti-calpain I and II staining was seen in hippocampus. As is shown in Figure 6, anti-calpain I stained mainly pyramidal cells, while anti-calpain II predominantly stained glial cells. The staining intensity of anti-calpain I was strongest in the cell body and decreased rapidly in the proximal dendrites. Here again, as in the cerebellum, no positive reaction was seen in the fine spiny branchlets of pyramidal cells. The same staining patterns were seen in dentate gyrus (Fig. 7). 

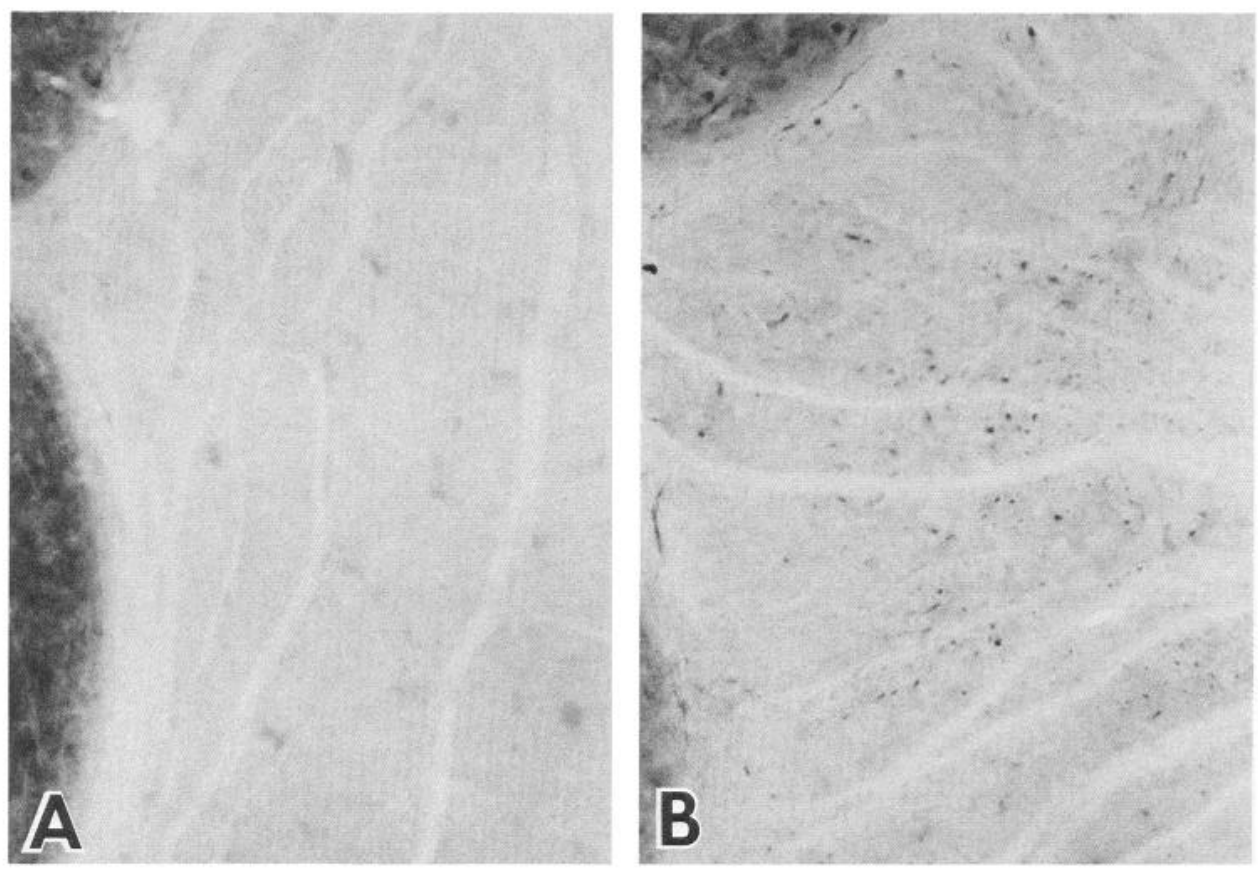

Figure 4. Adult rat cerebellum showing the central white matter stained for calpain I $(A)$ or II $(B)$. Magnification, $\times 100$.

\section{Distributional change during development}

We followed the staining pattern of both antibodies during the development of rat brain. Figure 8 shows sections of hippocampus where the distributional changes were most clearly observed. Anti-calpain I mainly stained neuronal cell bodies and their proximal dendrites at every age examined ( $0-45$ days). This was the same staining pattern as that in adult animals (older than 70 d; see Fig. 6). Anti-calpain II, however, produced a different pattern in young than in adult animals. The change of staining pattern occurred around $20 \mathrm{~d}$ after birth. In $0-, 10$-, and 15-dold rats, anti-calpain II reacted with neuronal cells and their dendrites, a pattern very similar to that obtained with anticalpain I. In 20-d-old rats, anti-calpain II also began to stain glial cells, while the staining intensity in neuronal cells decreased. In 45-d-old rats, the staining pattern of anti-calpain II was almost the same as that in adult animals. We also examined the staining pattern of both antibodies in a 2-year-old rat and found no difference from that in young adult rats, except that the immunoreaction was very weak (data not shown).

\section{Discussion}

We report in this paper the immunohistochemical localization of calpains I and II, 2 distinctive forms of $\mathrm{Ca}^{2+}$-dependent cysteine proteinases, in rat brain. The use of affinity-purified antibodies directed, respectively, against calpain I $\left(\mu \mathrm{M}-\mathrm{Ca}^{2+}-\mathrm{re}-\right.$ quiring form) and calpain II ( $\mathrm{mM}-\mathrm{Ca}^{2+}$-requiring form) enabled us to demonstrate common features as well as differences in their distribution in brain tissue.

One of the features common to both calpains I and II was that they were concentrated mainly in cell bodies. Proximal dendrites were stained, though to a lesser extent than cell bodies, but the distal portions were unstained (Figs. 3, 5, and 6). These results indicate that the cell body contains the major concentration of calpain protein. This suggests that the cell body is a major site of calpain action, but this is subject to the caveat that our present data do not prove that immunostained protein corresponds to active enzyme. Our results also support the proposition made by previous investigators (Ishizaki et al., 1983; Kamakura et al., 1983; Schlaepfer and Freeman, 1980) that calpain may be involved in the degradation of axonal proteins. Figure 4 shows that calpain II, not calpain I, is localized in the myelinated axons in the central white matter, making it possible that calpain II is the degradative enzyme responsible for Wallerian degeneration.

The uneven distribution of calpains I and II in different tissues has long been recognized (see, for review, Murachi, 1984). The present study shows that distinct differences between calpains I and II also exist at the cellular level. Throughout the brain, calpain I is mainly localized in neuronal cells, whereas calpain II is more prominent in glial cells. This may imply a difference in physiological function between calpains I and II. Although little is known about the in vivo actions of calpains, it has been proposed that they may act to terminate cytoskeletal extension under the regulation of calcium fluxes (Lasek and Hoffman, 1976). The presence of micromolar-activated calpain I in proximal segments of neuronal processes and of millimolar-activated calpain II in myelinated axons suggests that these 2 enzymes may program varying sensitivities of cytoskeletal structures to local calcium fluxes in different neuronal microdomains.

The differences in the cellular patterns of expression of calpains I and II during brain development suggest functional differences between the 2 enzymes. It is interesting to note that mature erythrocytes, like post-mitotic neurons, contain calpain I but not calpain II (Hatanaka et al., 1984; Murachi et al., 1981a), while almost all other tissues and cells so far examined contain both. During the early phase of brain development, we stained neurons with both anti-calpain I and anti-calpain II, and the disappearance of calpain II from these cells began at about postnatal day 20 , when the major phase of axon and dendrite growth is ending. This corresponds to the end of the period when neuronal microtubules undergo a transition in their chemical composition, which includes marked declines in neuronal levels of several microtubule-associated proteins (Bernhardt et al., 1985; Calvert and Anderton, 1985; Riederer and Matus, 1985).

Lynch and Baudry (1984) have proposed a hypothesis that the calpain I associated with post-synaptic membranes of synapses on hippocampal neurons plays a role in the mechanism of memory. They recovered the enzyme from crude subcellular fractions containing synaptosomal plasma membrane and dem- 

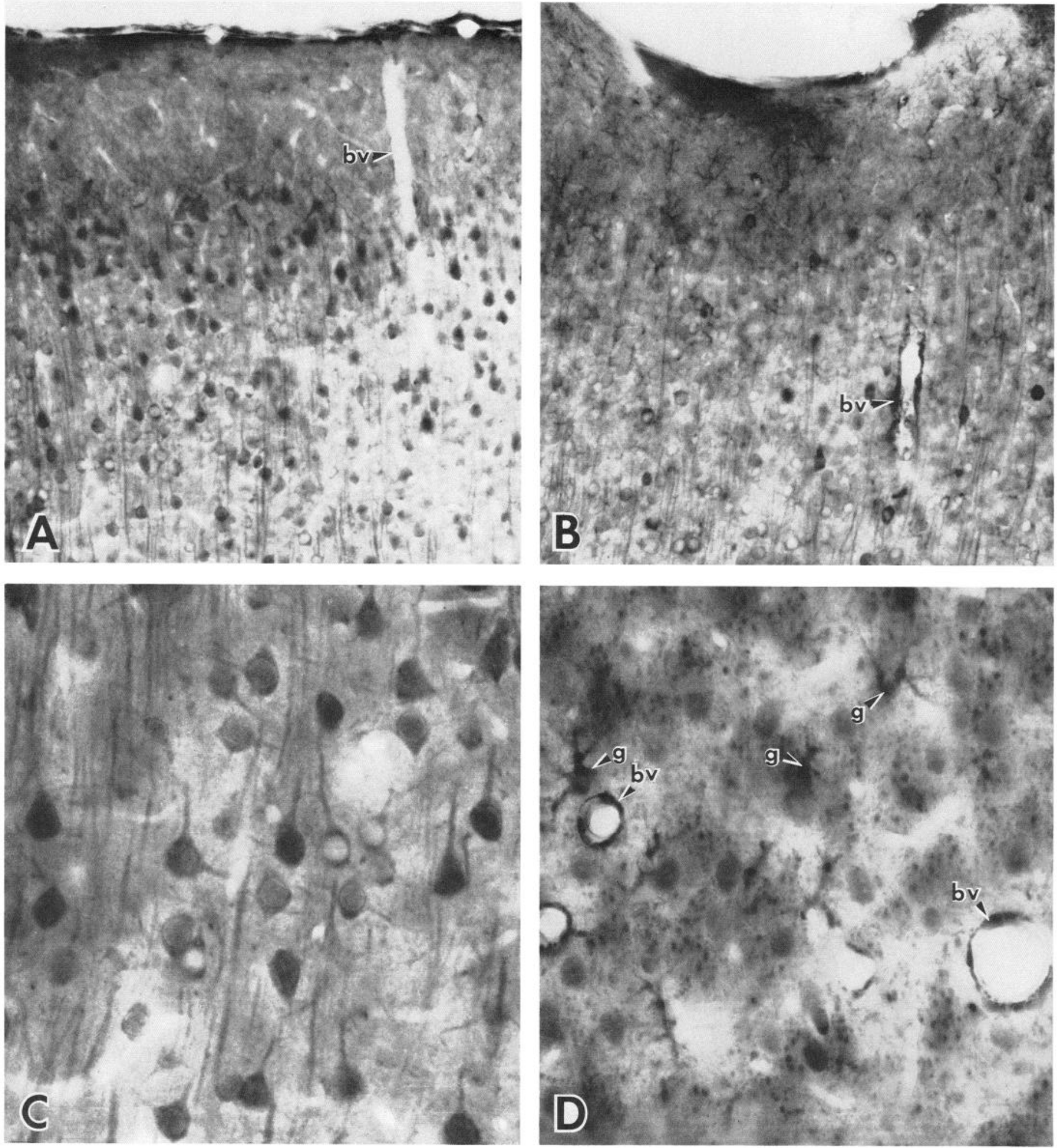

Figure 5. Adult rat neocortex stained with anti-calpain I $(A, C)$ or II $(B, D)$. Blood vessels $(b v)$ and astoglial cells $(g)$ are indicated. $A$ and $B$, Outer layer, including pial surface. Magnification, $\times 100$. $C$ and $D$, Layer V. Magnification, $\times 320$. 

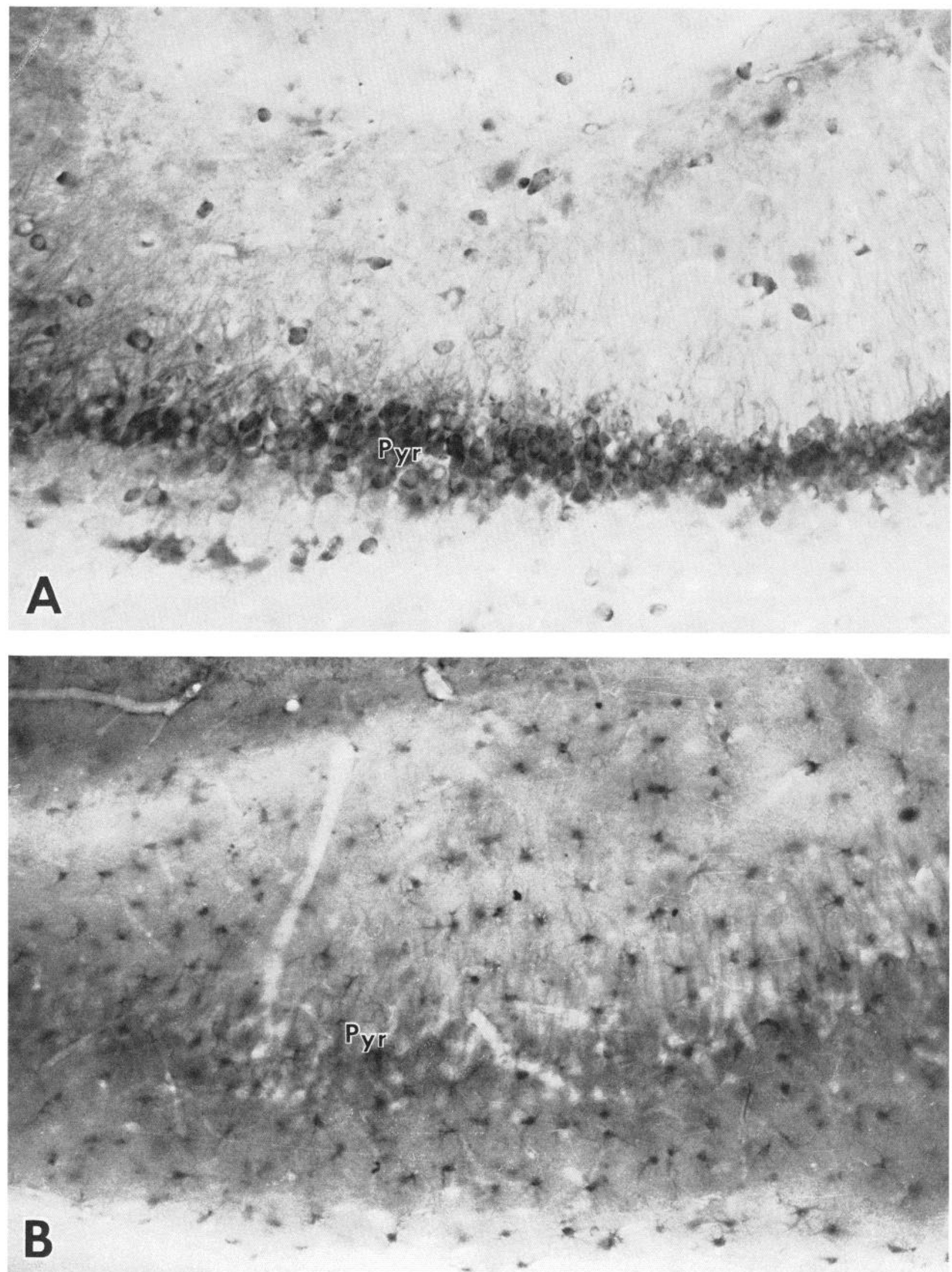

Figure 6. Rat hippocampus area CA1 stained with anti-calpain I $(A)$ or II $(B)$. The layer of pyramidal cell bodies $(P y r)$ is indicated in each case. Magnification, $\times 125$. 

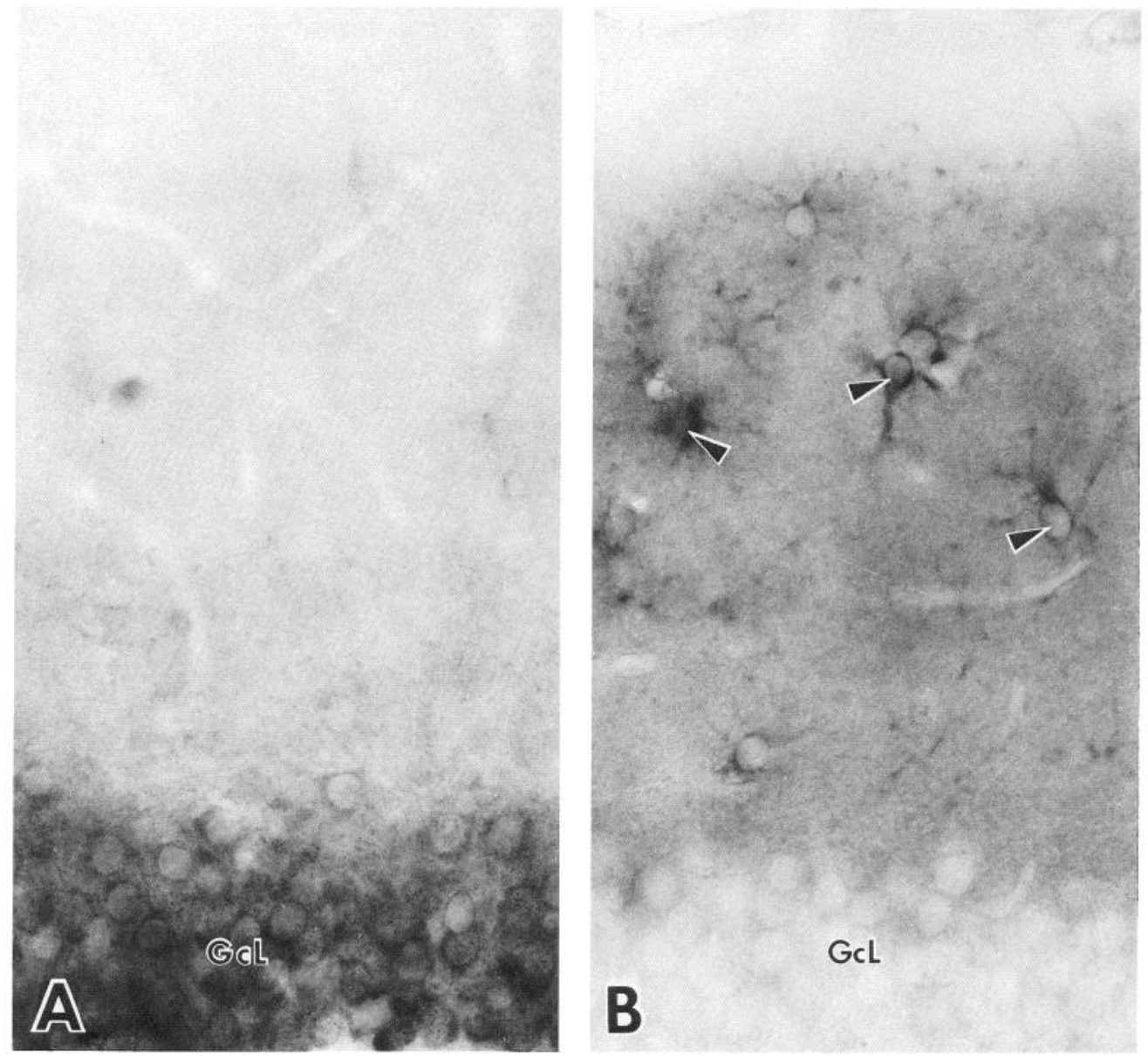

Figure 7. Dentate gyrus, showing staining patterns with anti-calpain I $(A)$ or II $(B)$. The granule cell body layer $(G c L)$ is indicated. In $B$, stained astroglial cells are marked with arrowheads. Magnification, $\times 300$.

onstrated that it up-regulated the number of glutamate receptors by cleaving fodrin in a $\mathrm{Ca}^{2+}$-dependent manner. If this were the case, then positive staining with anti-calpain I would be expected at synaptic sites on dendrites in hippocampus, where the glutamate receptors are known to be abundant. Contrary to this expectation, we found no such membrane-associated localization of calpain I, either in hippocampus (Fig. 6), neocortex (Fig. 5 ), or cerebellum (Fig. 3). It is unlikely that this was the result of a failure in the immunohistochemical methods we employed because, using exactly the same techniques, we were able to stain dendritic spines with anti-actin (Matus et al., 1982) and locate synaptic plasma membrane proteins at synapses (Matus et al., 1984).

There is thus a discrepancy between the recovery of calpain from membranes by Siman et al. (1983) and the absence of synaptic staining by anti-calpain reported here. One possible explanation lies in the nature of the membranes that Siman et al. used. They were derived, not from synaptosomes, but from the crude $\mathrm{P}_{2}$ pellet that contains membranes of mitochondrial, myelin, and undefined origin. Such preparations are well suited to investigating neurotransmitter receptors, where the object under study is defined by its pharmacological properties (Snyder and Goodman, 1980), but, because of their heterogeneity, it is difficult to use them to unequivocally identify a protein with a specific subcellular organelle. Siman et al. (1983) extracted calpain from the $\mathrm{P}_{2}$ membranes by incubating them overnight in low-ionic-strength buffer, indicating that the recovered calpain was weakly attached to the membrane periphery. It is known that synaptic membranes, and particularly the synaptic junctional structures they contain, bind foreign proteins in brain homogenates nonspecifically. This has been demonstrated for myelin basic protein (Cohen et al., 1977) and neurofilament proteins (Matus et al., 1980). The same possibility exists for soluble proteins such as the calpains that in tissue homogenates may adsorb to synaptic membranes to which they are not normally exposed in intact cells. Despite these problems, it is still possible that membrane-associated calpain exists in a form with different antigenicity from cytosolic calpain I, or that the antigenic epitope of membrane-associated calpain is hidden by its association with other proteins or lipids. Nevertheless, the present results do not provide any direct support for the existence of a role for calpain I at the synaptic site.

After this manuscript was submitted for publication, Siman et al. (1985) published a report of the immunohistochemical localization of calpain I in the brain. Their results are similar to ours in that calpain I immunoreactivity occurs in neuronal cell bodies and is mainly concentrated in the soma and proximal dendrites. They also find calpain I antigen in glia and axon tracts, whereas our results suggest that calpain II is the predominant form at these sites.

\section{References}

Bernhardt, R., and A. Matus (1984) Light and electron microscopic studies of the distribution of microtubule-associated protein 2 in rat brain: A difference between dendritic and axonal cytoskeletons. J. Comp. Neurol. 226: 203-219. 

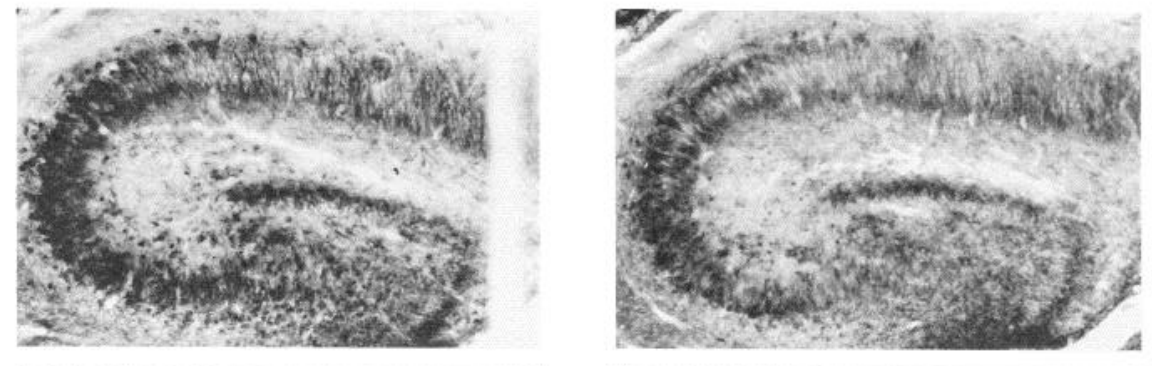

\section{Days of age}
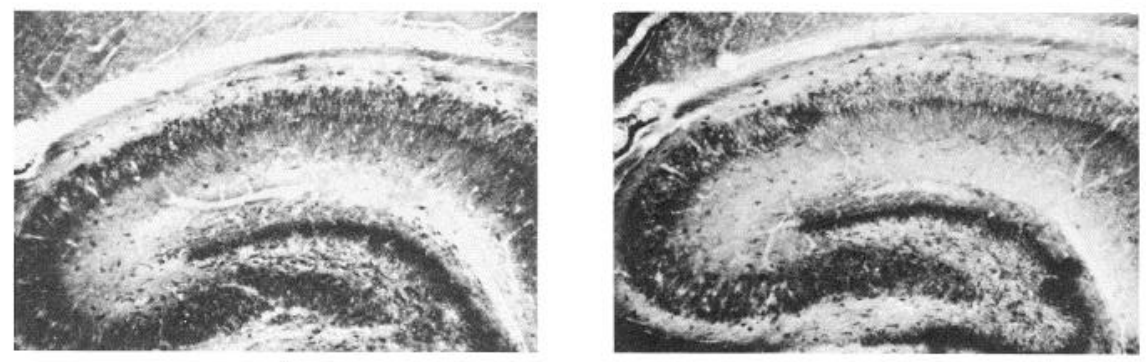

0
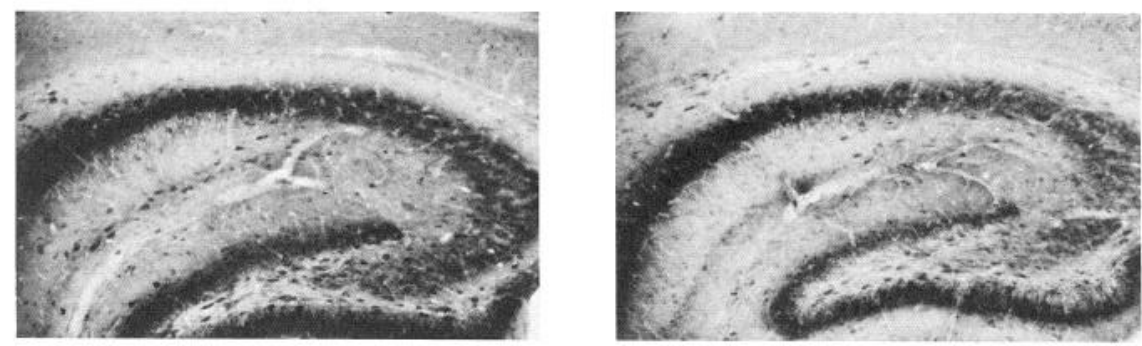

20
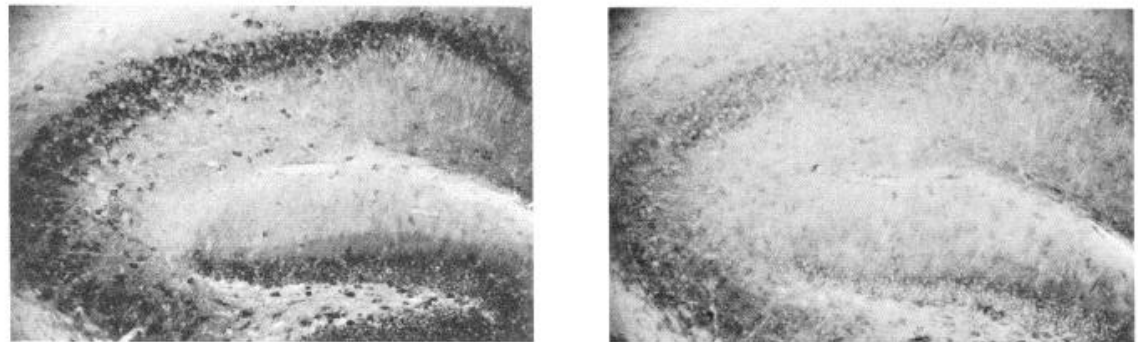

10

Figure 8. Sections of rat hippocampus from animals of various ages, as indicated on the right, stained with either anti-calpain I (left column) or II (right column). Magnification, $\times 20$.

Bernhardt, R., G. Huber, and A. Matus (1985) Differences in the developmental patterns of three microtubule-associated proteins in rat cerebellum. J. Neurosci. 5: 977-991.

Calvert, R., and B. Anderton (1985) A microtubule-associated protein (MAP1X) which is expressed at elevated levels during development in rat cerebellum. EMBO J. 4: 1171-1176.

Cohen, R. S., F. Blomberg, K. Berzins, and P. Siekevitz (1977) The structure of postsynaptic densities isolated from dog cerebral cortex. I. Overall morphology and protein composition. J. Cell Biol. 74: 181203.

Gilbert, D. S., and B. J. Newby (1975) Neurofilament disguise, destruction and discipline. Nature 256: 586-589.

Guroff, G. (1984) A neutral, calcium-activated protease from the soluble fraction of rat brain. J. Biol. Chem. 239: 149-155.

Hatanaka, M., N. Yoshimura, T. Murakami, R. Kannagi, and T. Murachi (1984) Evidence for membrane-associated calpain I in human erythrocytes. Detection by an immunoelectrophoretic blotting method using monospecific antibody. Biochemistry 23: 3272-3276.

Ishizaki, Y., T. Tashiro, and M. Kurokawa (1983) A calcium-activated protease which preferentially degrades the $160-\mathrm{kDa}$ component of the neurofilament triplet. Eur. J. Biochem. 131:41-45.

Kamakura, K., S. Ishiura, H. Sugita, and Y. Toyokura (1983) Identification of $\mathrm{Ca}^{2+}$-activated neutral protease in the peripheral nerve and its effects on neurofilament degeneration. J. Neurochem. 40:908913.

Kitahara, A., T. Sasaki, T. Kikuchi, N. Yumoto, N. Yoshimura, M. Hatanaka, and T. Murachi (1984) Large-scale purification of porcine calpain I and calpain II and comparison of proteolytic fragments of their subunits. J. Biochem. (Tokyo) 95: 1759-1766.

Laemmli, U. K. (1970) Cleavage of structural proteins during the assembly of the head bacteriophage T4. Nature 227: 680-685.

Lasek, R. J., and P. Hoffman (1976) The neuronal cytoskeleton, axonal transport and axonal growth. In Cell Motility, Vol. 3, T. Pollard and J. Rosenbaum, eds., pp. 1021-1049, Cold Spring Harbor Laboratory, Cold Spring Harbor, NY.

Lynch, G., and M. Baudry (1984) The biochemistry of memory: A new and specific hypothesis. Science 224: 1057-1063.

Matus, A., G. Pehling, M. Ackermann, and J. Maeder (1980) Brain postsynaptic densities: Their relationship to glial and neuronal filaments. J. Cell Biol. 87: 346-359.

Matus, A., M. Ackermann, G. Pehling, H. R. Byers, and K. Fujiwara (1982) High actin concentrations in brain dendritic spines and postsynaptic densities. Proc. Natl. Acad. Sci. USA 79: 7590-7594.

Matus, A., M. Ng, G. Pehling, M. Ackermann, and K. Hauser (1984) Surface antigens of brain synapses: Identification of minor proteins using polyclonal antisera. J. Cell Biol. 98: 237-245. 
Mellgren, R. L. (1980) Canine cardiac calcium-dependent protease: Resolution of two forms with different requirements for calcium. FEBS Lett. 109: 129-133.

Murachi, T. (1984) Calcium-dependent proteinases and specific inhibitors: Calpain and calpastatin. Biochem. Soc. Symp. 49: 149-167.

Murachi, T., M. Hatanaka, Y. Yasumoto, N. Nakayama, and K. Tanaka (1981a) A quantitative distribution study on calpain and calpastatin in rat tissues and cells. Biochem. Int. 2: 651-656.

Murachi, T., K. Tanaka, M. Hatanaka, and T. Murakami (1981b) Intracellular $\mathrm{Ca}^{2+}$-dependent protease (calpain) and its high-molecular-weight endogenous inhibitor (calpastatin). Adv. Enzyme Reg. 19: 407-424.

Pant, H. C., S. Terakawa, and H. Gainer (1979) A calcium-activated protease in squid axoplasm. J. Neurochem. 32: 99-102.

Riederer, B., and A. Matus (1985) Differential expression of distinct microtubule-associated proteins during brain development. Proc. Natl. Acad. Sci. USA 82: 6006-6009.

Sasaki, T., T. Kikuchi, N. Yumoto, N. Yoshimura, and T. Murachi (1984) Comparative specificity and kinetic studies on porcine calpain I and calpain II with naturally occurring peptides and synthetic fluorogenic substrates. J. Biol. Chem. 259: 12489-12494.

Schlaepfer, W. W., and L. A. Freeman (1980) Calcium-dependent degradation of mammalian neurofilaments by soluble tissue factors from rat spinal cord. Neuroscience 5: 2305-2314.

Siman, R., M. Baudry, and G. Lynch (1983) Purification from synaptosomal plasma membranes of calpain $I$, a thiol protease activated by micromolar calcium concentrations. J. Neurochem. 41: 950-956.

Siman, R., C. Gall, L. S. Perlmutter, C. Christian, M. Baudry and G. Lynch (1985) Distribution of calpain I, an enzyme associated with degenerative activity, in rat brain. Brain Res. 347: 399-403.

Snyder, S. H., and R. R. Goodman (1980) Multiple neurotransmitter receptors. J. Neurochem. 35: 5-15.

Towbin, H., T. Staehelin, and J. Gordon (1979) A procedure for the electrophoretic transfer of proteins from polyacrylamide gels to nitrocellulose sheets and some applications. Proc. Natl. Acad. Sci. USA 76: 4350-4354.

Wheelock, M. J. (1982) Evidence for two structurally different forms of skeletal muscle $\mathrm{Ca}^{2+}$-activated protease. J. Biol. Chem. 257: 1247112474.

Yoshimura, N., N. Hatanaka, A. Kitahara, N. Kawaguchi, and T. Murachi (1984) Intracellular localization of two distinct $\mathrm{Ca}^{2+}$-proteases (calpain I and calpain II) as demonstrated by using discriminative antibodies. J. Biol. Chem. 259: 9847-9852. 